\title{
Study the Band Energy Structure and Absorption Coefficient for PbSe Thin Films
}

\author{
Tariq J.Alwan* Abbas.K.Hassen** \\ Date of acceptance 13/1/2008
}

\begin{abstract}
The PbSe alloy was prepared in evacuated quarts tubs by the method of melt quenching from element, the PbSe thin films prepared by thermal evaporation method and deposited at different substrate temperature $\left(\mathrm{T}_{\mathrm{s}}\right)=\mathrm{R}$.T ,373 and $473 \mathrm{~K}$.

The thin films that deposited at room temperature (R.T=303)K was annealed at temperature, $\mathrm{T}_{\mathrm{a}}=$ R.T, 373 and $473 \mathrm{~K}$.

By depended on D.C conductivity measurements calculated the density of state (DOS), The density of extended state $\mathrm{N}\left(\mathrm{E}_{\mathrm{ext}}\right)$ increases with increasing the $\mathrm{T}_{\mathrm{s}}$ and $\mathrm{T}_{\mathrm{a}}$, while the density of localized state $\mathrm{N}\left(\mathrm{E}_{\mathrm{loc}}\right)$ is decreased .

We investigated the absorption coefficient $(\alpha)$ that measurement from reflection and transmission spectrum result, and the effect of $T_{s}$ and $T_{a}$ on it, also we calculated the tail width for each prepared films.
\end{abstract}

\section{Introduction:}

Lead Selenide is considered to be one of the most important material for fabrication of infrared detectors because it is highly sensitive and has a fast response on infrared radiation when sensitized with sensitizer ( for example oxygen ). [1] Application of $\mathrm{PbSe}$ detector are found in many areas of industry and medical fields. In agriculture it is used in master analyzer to determine the water content of a product. It appears in combustion -control aperture for power-generation plants as well as in pollution - control instruments $[2,3]$.

The interest in the optical properties of chalcogenide compounds containing metal atoms has been established by their potential applications as switching and memory devices and optical transmission media, as well as by their use as passivating materials for integrated circuits. It is well known that the optical properties and effect of temperature on it [4].

Lead Selenide is a polar semiconductor with sodium-chloride like structure [5]. The bonding is largely found to be due to electrostatic force between the ions forming the crystal the space lattice is FCC [6] with lattice parameter $\left(\mathrm{a}=6.122 \mathrm{~A}^{\mathrm{o}}\right)$.the melting point of $\mathrm{PbSe}$ is (1338K) [7] .

Amorphous material is characterized by a pseudo sharp edge at ends of conduction and valence bands, but there is gradual decline peak of valence band and bottom of conduction band, to word energy gap, so these materials do not have true energy gap but (pseudo) gap called mobility gap, [8]. The defect in structure of amorphous materials could lead to localized states as a tails above and below the extended states [9] .

*Department of Physics College of Education, Al Moustinsriay University, E-mail :- tariqjaffar@yahoo.com

**Department of Physics College of Science, Al Moustinsriay University, E-mail:- abbasphysics@yahoo.com 
There are several models that are put to understand the structure of bands in the material, \{Cohen-FritizcheOvshimsicy (CFO) model, Mott -Davis model and Marshal-Owen model\} [10] and the Fig.(1) shows this models [10]

Mott-Davis is the model that agreement with the band structure of Chalcogenide glass, by this model we can understand the phenomena of D.C conductive and optical transition in it.

Mott-Davis suggested that the tails of localized states are rather narrow and extended few tenth of electron volts in the forbidden gap, which depend on the degree of disorder. The exsistence of dangling bonds in the amorphous semiconductors. The exsistence of dangling bonds and impurities produce a few localized states in the gap as Fig.(1- b). [7,10]

This study deals with the effect of $T_{a}$ and $T_{s}$ on the DOS (Density of state ) and absorption coefficient $(\alpha)$ for $\mathrm{PbSe}$ thin films.

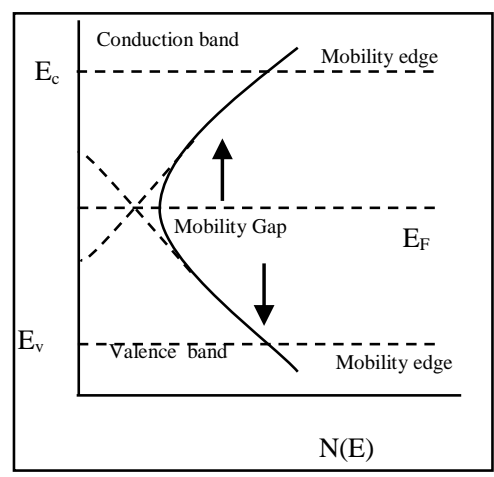

(a)

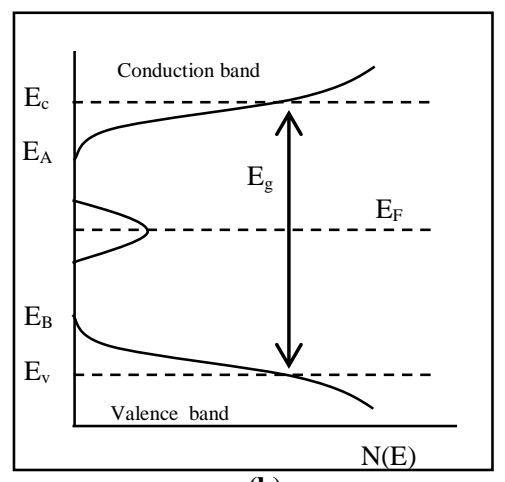

(b)

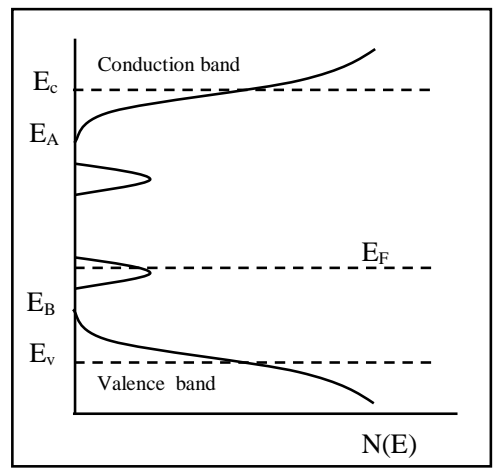

(c)

Fig. (1) Density of states in amorphous semiconductors . a) CFO model, b)MottDaivs model, c) Marshal -Owen model. [10]

\section{Experimental Technique}

To prepare the alloy we have used highly pure $\mathrm{Pb}$ and Se element (99.999\%) according to the alloy have been pleased in a quartz tube .which attached to the evacuated system the tube has been sealed at pressure $10^{-3}$ mbar and placed in an electrical furnace heated to a temperature at $1373 \mathrm{~K}$ which is above the melting point of lead $(600 \mathrm{~K})$, Selenium (450K) and lead Selenide alloy (1338K), for four hours, after that the tube has been quenched rapidly in cold water.

The PbSe thin films of thickness 3000A have been prepared by used Edward coating unit model (306A), from the alloy by thermal evaporation method in $8 * 10^{-5}$ mbar pressure at different substrate temperate $\left(\mathrm{T}_{\mathrm{s}}=\mathrm{R} . \mathrm{T}, 373 \& 473\right.$ $\mathrm{K})$ and at rate of $25 \mathrm{~A} / \mathrm{sec}$. the film that deposition at room temperature substrate, have annealed at different temperature $\left(\mathrm{T}_{\mathrm{a}}=\mathrm{R} . \mathrm{T}, 373 \& 473 \mathrm{~K}\right)$

We used optical interference fringes method to determine the thickness of films.

We measurement the D.C conductivity for each films to used this result in calculated the DOS .The FTIR spectrophotometer is used to carryout the absorption and transmission spectrum in the $2-5 \mu \mathrm{m}$ region for the $\mathrm{PbSe}$ thin films 
deposited single crystal Silicon wafer (111) substrate.

\section{Result and Discussion}

\section{Density of States}

By dependent on the D.C conductivity to find $\left(\sigma_{\circ}\right)$, as Fig. (2-I,II) path a the extrapolation of $\ln \sigma$ to $1 / \mathrm{T}=0$ gives $\left(\sigma_{\mathrm{o}(\mathrm{ext})}\right)$.and path $\mathrm{b}$ gives $\left(\sigma_{\mathrm{o}(\mathrm{loc})}\right)$, we measurement the density of extended states by use the equation [11]
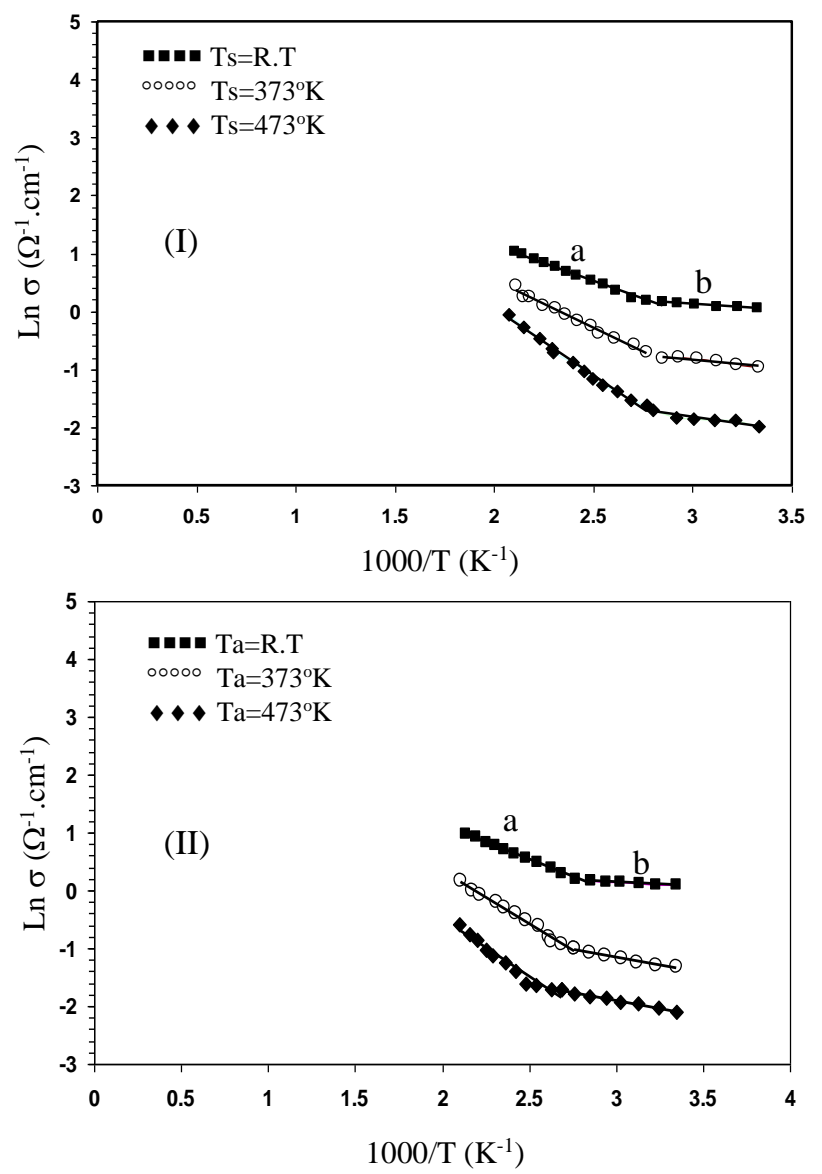

Fig. (2) Variation of $\operatorname{Ln} \sigma \mathrm{vs.1000/T}$ for PbSe Thin film I) Deposited at different substrata Temp. II)Annealing for different Temp.

$$
\mathrm{N}\left(\mathrm{E}_{\mathrm{ext}}\right)=\frac{6 \mathrm{~m}}{\mathrm{e}^{2} \hbar} \sigma_{\circ}(\mathrm{ext})
$$

Where

$\mathrm{N}\left(\mathrm{E}_{\text {ext }}\right)=$ Density of extended state $\sigma_{0}=$ Conductivity at $0^{\circ} \mathrm{K}$ $\hbar=1.0545 * 10^{-34} \mathrm{~J} . \mathrm{s}$

The value of density of extended state are listed in Table (1-a,b), that show the density of extended state $\left(\mathrm{N}\left(\mathrm{E}_{\text {ext }}\right)\right.$ increase with increase the substrate temperature from $1.309 \times 10^{21}\left(\mathrm{eV}^{-1} \cdot \mathrm{cm}^{-3}\right)$ at R.T to $3.556 \times 10^{21}\left(\mathrm{eV}^{-1} \cdot \mathrm{cm}^{-3}\right)$ at $473^{\circ} \mathrm{K}$.

From this Table also see the effect of $T_{s}$ on the density of localize state that calculated by the eq. [11]

$$
N\left(E_{l o c}\right)=\frac{6\left(\sigma_{o}\right)_{l o c}}{e^{2} v_{p h} R^{2}}
$$

Where

$\left(\sigma_{\mathrm{o}}\right)_{\text {loc }}=$ the conductivity at $0^{\circ} \mathrm{K}$

$v_{\mathrm{ph}}=$ phonon frequency and of order $10^{13} \mathrm{~s}^{-1}$

$\mathrm{R}=$ hopping distance and is give by [9]

$$
R=0.7736\left|\frac{\Delta E \gamma^{-1}}{N\left(E_{e x t}\right)\left(K_{B} T\right)^{2}}\right|^{1 / 4}
$$

$\Delta \mathrm{E}=$ the tail width

$\gamma^{-1}=10 \mathrm{~A}$

$\mathrm{K}_{\mathrm{B}}=$ Boltezman constant

The density of localized state was decreased with increasing $\mathrm{T}_{\mathrm{s}}$ from $3.192 \times$ $10^{18}\left(\mathrm{eV}^{-1} \cdot \mathrm{cm}^{-3}\right)$ at R.T to $2.062 \times 10^{18}$ $\left(\mathrm{eV}^{-1} \cdot \mathrm{cm}^{-3}\right) 473 \mathrm{~K}$,

The increase in density of extended and the decrease in localized state can by interpretation this result to the increasing of substrate temperature has a great effect to change the structure of the films, from amorphous to polycrystalline state. [12].

The effected of $T_{a}$ on the density of state of the PbTe films that deposited at R.T and annealing to different temperature $\left(\mathrm{T}_{\mathrm{a}}=\mathrm{R} \cdot \mathrm{T}, 373^{\circ}, 437^{\circ} \mathrm{K}\right)$, has been listed in Table (1-b) .

From this Table we see the density of extended state is increased with increasing the annealing temperature from $1.309 \times 10^{21}\left(\mathrm{eV}^{-1} \cdot \mathrm{cm}^{-3}\right)$ at R.T to $4.345 \times$ $10^{21}\left(\mathrm{eV}^{-1} \cdot \mathrm{cm}^{-3}\right)$ at $\mathrm{T}_{\mathrm{a}}=473 \mathrm{~K}$. while the density of localized state decreases with $\mathrm{T}_{\mathrm{a}}$ from $3.192 \times 10^{18}\left(\mathrm{eV}^{-1} \cdot \mathrm{cm}^{-3}\right)$ at R.T to $2.526 \times 10^{18}\left(\mathrm{eV}^{-1} . \mathrm{cm}^{-3}\right)$ at $473^{\circ} \mathrm{K}$. 
This result of increasing in density of extended state and decrease in the density of localized state with $\mathrm{T}_{\mathrm{a}}$ can be interpretation to the decrease of structure defect and the increase of grain size with $\mathrm{T}_{\mathrm{a}}$ increasing .[13].

Both increase in $T_{a}$ and $T_{s}$ effect on activation energy for extended state $\left(\mathrm{Ea}_{\mathrm{ext}}\right)$ and activation energy for localized state $\left(\mathrm{Ea}_{\mathrm{loc}}\right)$ for $\mathrm{PbSe}$ thin films, and these are listed in Table (1-a,b).

\section{Optical Absorption}

The most important absorption process involves the transition of electrons from the valence to conduction band, Because of its important process is sometime called the " fundamental absorption "

In the fundamental absorption, an electron absorbs a phonon (from the incident beam), and jumps from the valence band to conduction band. The photon energy must be equal to the energy gap or larger. [14]

The relation used to given absorption coefficient $(\alpha)$ [14].

$\alpha=2.303\left(\frac{\mathrm{A}}{\mathrm{t}}\right)$.

where $\mathrm{A}$ is the absorptance and $\mathrm{t}$ is the thickness of the film.

In the present study, Fig (3-I \& II) show the variation of absorption coefficient $(\alpha)$ for $\mathrm{PbSe}$ films that calculated by eq.(1), with photon energy (hv) at different substrate and annealing temperature respectively, It is clear the effect of $\mathrm{T}_{\mathrm{s}}$ and $\mathrm{T}_{\mathrm{a}}$, shifts the absorption coefficient spectra to higher energies . The $\alpha$ value in general decreases with increasing the $T_{s}$ and $T_{a}$ because this effected on structure of films, through decrease the defect structure films, and increase the crystallization[12].

Hence the tail width decreasing for both effect of $\mathrm{T}_{\mathrm{s}} \& \mathrm{~T}_{\mathrm{a}}$, as we see in Table
$(1, a \& b)$, and this agreement with our DOS results.
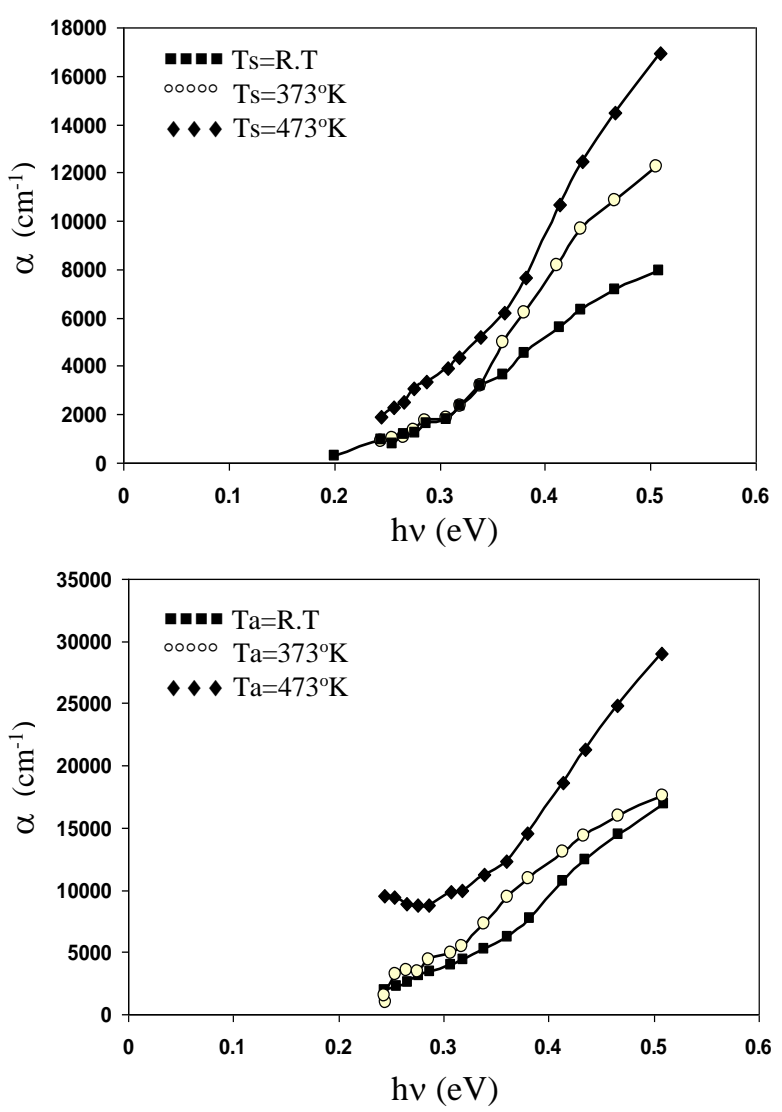

Fig. (3) Variation of $\alpha$ vs. hv for PbSe $\begin{array}{ll}\text { Thin film } & \text { I) Deposited at different }\end{array}$ substrata Temp. II)Annealing for different Temp.

\section{Conclusion}

The effect of substrate and annealing temperatures have very clear on the density of states for PbSe thin films, We found the density of extended state increases when we increase the $T_{s}$ and $T_{a}$, while the density of localized state was decreased. This lead to effect on optical properties of $\mathrm{PbSe}$ films, where absorption coefficient decreases with this effected, also we found the tail width decreases with increasing the substrate and annealing temperatures, all the happened because the Ts and Ta change the structure of films from amorphous to crystalline. 
Table (1). Values of $\mathrm{N}\left(\mathbf{E}_{\text {ext }}\right), \mathrm{N}\left(\mathrm{E}_{\text {loc }}\right), \mathbf{E a}\left(\right.$ ext) $, \sigma_{o(\mathrm{ext})}, \mathrm{Ea}_{(\mathrm{loc})}, \sigma_{\mathrm{o}(\mathrm{loc})}, \Delta \mathrm{E}$ and $\mathrm{R}$ at different a) Substrate temp. b) Annealing temp.

\begin{tabular}{|c|c|c|c|c|c|c|c|c|}
\hline \multicolumn{9}{|c|}{ (a) } \\
\hline Ts $\mathrm{K}^{\mathrm{o}}$ & $\mathrm{Ea}_{(\mathrm{ext})}(\mathrm{eV})$ & $\begin{array}{c}\sigma_{\mathrm{o}(\mathrm{ext})} \\
\left(\Omega^{-1} \cdot \mathrm{cm}^{-1}\right)\end{array}$ & $\begin{array}{c}\mathrm{N}\left(\mathrm{E}_{\mathrm{ext}}\right) \\
\left(\mathrm{eV}^{-1} \cdot \mathrm{cm}^{-3}\right)\end{array}$ & $\begin{array}{c}\mathrm{Ea}_{(\mathrm{loc})} \\
(\mathrm{eV})\end{array}$ & $\begin{array}{c}\sigma_{\mathrm{o}(\mathrm{loc})} \\
\left(\Omega^{-1} \cdot \mathrm{cm}^{-1}\right)\end{array}$ & $\begin{array}{c}\Delta \mathrm{E} \\
(\mathrm{eV})\end{array}$ & $\mathrm{R}(\mathrm{cm})$ & $\begin{array}{c}\mathrm{N}\left(\mathrm{E}_{\mathrm{loc}}\right) \\
\left(\mathrm{eV}^{-1} \cdot \mathrm{cm}^{-3}\right)\end{array}$ \\
\hline R.T & 0.103 & 40.4 & $1.307 \times 10^{21}$ & 0.019 & 1.768 & 0.0868 & $4.55 \times 10^{-7}$ & $3.192 \times 10^{18}$ \\
\hline 323 & 0.140 & 60.34 & $1.952 \times 10^{21}$ & 0.029 & 1.105 & 0.0754 & $3.97 \times 10^{-7}$ & $2.616 \times 10^{18}$ \\
\hline 473 & 0.196 & 109.9 & $3.556 \times 10^{21}$ & 0.039 & 0.606 & 0.0665 & $3.31 \times 10^{-7}$ & $2.062 \times 10^{18}$ \\
\hline
\end{tabular}

(b)

\begin{tabular}{|c|c|c|c|c|c|c|c|c|}
\hline $\mathrm{Ta} \mathrm{K}^{\mathrm{o}}$ & $\mathrm{Ea}_{\text {(ext) }}(\mathrm{eV})$ & $\begin{array}{c}\sigma_{\text {o(ext) }} \\
\left(\Omega^{-1} . \mathrm{cm}^{-1}\right)\end{array}$ & $\begin{array}{c}\mathrm{N}\left(\mathrm{E}_{\text {ext }}\right) \\
\left(\mathrm{eV}^{-1} \cdot \mathrm{cm}^{-3}\right)\end{array}$ & $\begin{array}{c}\mathrm{Ea}_{\text {(loc) }} \\
(\mathrm{eV})\end{array}$ & $\begin{array}{c}\sigma_{\text {o(loc) }} \\
\left(\Omega^{-1} . \mathrm{cm}^{-1}\right)\end{array}$ & $\begin{array}{c}\Delta \mathrm{E} \\
(\mathrm{eV})\end{array}$ & $\begin{array}{c}\mathrm{R} \\
\left(\mathrm{cm}^{2}\right)\end{array}$ & $\begin{array}{c}\mathrm{N}\left(\mathrm{E}_{\text {loc }}\right) \\
\left(\mathrm{eV}^{-1} . \mathrm{cm}^{-3}\right)\end{array}$ \\
\hline R.T & 0.103 & 40.4 & $1.307 \times 10^{21}$ & 0.019 & 1.768 & 0.0868 & $4.55 \times 10^{-7}$ & $3.192 \times 10^{18}$ \\
\hline 323 & 0.157 & 73.69 & $2.384 \times 10^{21}$ & 0.0477 & 1.648 & 0.0273 & $2.93 \times 10^{-7}$ & $7.166 \times 10^{18}$ \\
\hline 473 & 0.172 & 134.28 & $4.345 \times 10^{21}$ & 0.0471 & 0.406 & 0.0243 & $2.45 \times 10^{-7}$ & $2.526 \times 10^{18}$ \\
\hline
\end{tabular}

\section{References}

1- Saloniemi,

H. $\quad 2000$

Electrodeposition of $\mathrm{PbS}, \mathrm{PbSe}$ and

PbTe Thin Films. Technical

Research Center of Finland, VTT

Publications, ESPOO, 423, pp.11.

2- Delin, A., P. Ravindran , $\mathrm{O}$. Eriksson, \& J. M. Wills, 1998. FullPotential Optical Calculations of Lead Chalcogenides. Inter. J. of Quantum Chemistry. 69 (3) :353358.

3- Harris , S. E., 1983. Microwave Excitation of Excimer Lasers. Laser Focus. 24: 63-67.

4- Wahab, L.A., H.H. Amer, 2005. Composition Dependence of Optical Constants $\mathrm{Ge}_{1-\mathrm{x}} \mathrm{Se}_{2} \mathrm{~Pb}_{\mathrm{x}}$ Thin Films. Egypt J. Solids. 28(2): 255-261.

5- Chelikowsky, J. R., 2005. Simulating Liquid GeTe. Meter. Res. Soc. Symp. Proc. 918: 349-354.

6- Chizhikov , D.M., V.P. Shchastlivy, 1968. Selenium and Selenides. Collets, London, pp.164.

7- Hansen , M. \& K.Anderko, 1958. Constitution of Bing Alloys. McGraw-Hill, New York, pp.104.

8- Streetma, B.G., 1980. Solid State Electronic Devices, 2ed. PrenticeHall, Englewood Cliffs. pp.236.
9- Grant A.J. \& E.A. Davis, 1974. Hopping Conduction in Amorphous Semiconductors . Solid State Comm. 15: 566-569.

10-Brodsky, M.H., 1979. Topics in Applied Physics Amorphous Semiconductor. Pringer, Heidelberg, pp. 256

11-Jassim, K.A. , 1992. Effect of Composition Percent and Hydrogenation the Density of States of Amorphous Chaclcogenide Semiconductor. M.Sc Thesis, Coll. of Science, Univ. of Baghdad .

12- Jassim A.K. ， 2000. D.C Conductivity Transport Mechanism and Optical Properties of PbSe Thin films. M.Sc Thesis, Coll. of Science, Univ. of Baghdad.

13- Dadrlat， D., R.M.Canda， R.Turcu, I.P.Biro, I.I Zasavttskii, M.V. Valeiko \& A.P.Shotov, 1988. Size Effects in Polycrystalline $\mathrm{PbSe}$ Films Obtained by Chemical Deposition. Phys. State Sol. (a)108 :637-641

14- Jenkins, F. A. \&, H. E. White, 1981. Fundamentals of Optics. McGraw-Hill, New York, pp.234. 


\section{دراسة تركيب حزم الطاقة و معامل الامتصاص لاغثية PbSe الرقيقة}

** عباس كمال حسن

\section{* طارق جعفر علوان}

*قسم الفيزياء, كلبة التربية , الجامعة المستتصرية ، الجية

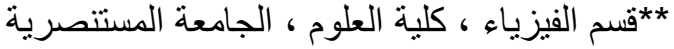

تم تحضير سبيكة من PbSe في انبوبـة من الكوارتز مفر غـة من الهواء بطريقة التبريد المفاجئة ـ الاغشية

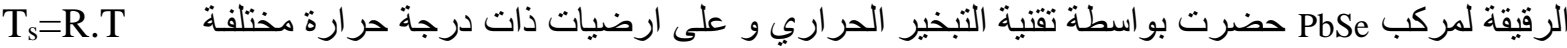

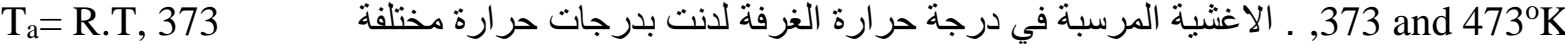
. and $473^{\circ} \mathrm{K}$

بالاعتماد على قياسات التوصيلية المستمرة نم حساب كثافة الحالات ـازدادت كثافة الحالات الممتدة بزيادة كل

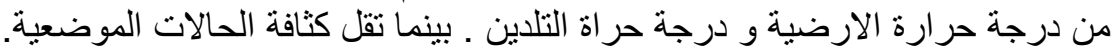

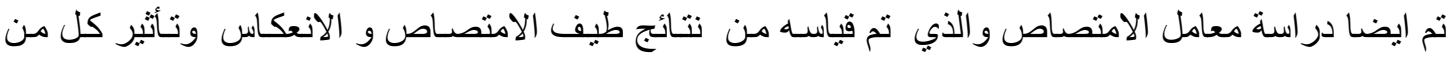

درجة حرارة الارضية و درجة حرارة التلدين عليه ، ايضا تم حساب عرض الذيول دلفي لكل الاغشية المحضرة . 